\title{
BMJ Open Usage of purchased self-tests for HIV and sexually transmitted infections in Amsterdam, the Netherlands: results of population-based and serial cross- sectional studies among the general population and sexual risk groups
}

To cite: Bil JP, Prins M, Stolte IG, et al. Usage of purchased self-tests for HIV and sexually transmitted infections in Amsterdam, the Netherlands: results of population-based and serial cross-sectional studies among the general population and sexual risk groups. BMJ Open 2017;7:e016609. doi:10.1136/ bmjopen-2017-016609

- Prepublication history for this paper is available online. To view these files please visit the journal online (http://dx.doi org/10.1136/bmjopen-2017016609).

Received 24 February 2017 Revised 19 July 2017 Accepted 4 August 2017

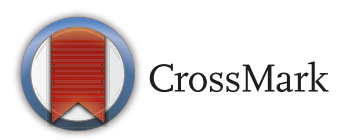

For numbered affiliations see end of article.

Correspondence to

Janneke P Bil;

jbil@ggd.amsterdam.nl

\section{ABSTRACT}

Objectives There are limited data on the usage of commercially bought self-tests for HIV and other sexually transmitted infections (STIs). Therefore, we studied HIV/STI self-test usage and its determinants among the general population and sexual risk groups between 2007 and 2015 in Amsterdam, the Netherlands.

Setting Data were collected in four different studies among the general population (S1-2) and sexual risk groups (S3-4).

Participants S1-Amsterdam residents participating in representative population-based surveys (2008 and 2012; $n=6044$ ) drawn from the municipality register; S2-Participants of a population-based study stratified by ethnicity drawn from the municipality register of Amsterdam (2011-2015; n=17603); S3-Men having sex with men (MSM) participating in an HIV observational cohort study (2008 and 2013; $n=597$ ) and S4-STI clinic clients participating in a cross-sectional survey (20072012; $n=5655$ ).

Primary and secondary outcome measures Prevalence of HIV/STI self-test usage and its determinants.

Results The prevalence of HIV/STI self-test usage in the preceding 6-12 months varied between $1 \%$ and $2 \%$ across studies. Chlamydia self-tests were most commonly used, except among MSM in S3. Chlamydia and syphilis self-test usage increased over time among the representative sample of Amsterdam residents (S1) and chlamydia self-test usage increased over time among STI clinic clients (S4). Self-test usage was associated with African Surinamese or Ghanaian ethnic origin (S2), being woman or MSM (S1 and 4) and having had a higher number of sexual partners (S1-2). Among those in the general population who tested for HIV/STI in the preceding 12 months, $5-9 \%$ used a self-test.

Conclusions Despite low HIV/STI self-test usage, we observed increases over time in chlamydia and syphilis self-test usage. Furthermore, self-test usage was higher among high-risk individuals in the general population. It is important to continue monitoring self-test usage and informing the public about the unknown quality of
Strenghts and limitations of this study

- The study included data from four different studies with large sample sizes among both the general population and sexual risk groups in Amsterdam, the Netherlands.

Data were collected between 2007 and 2015, which enabled us to estimate (temporal) trends in HIV/ sexually transmitted infection self-test usage.

- The results are limited to the use of self-tests in Amsterdam, the Netherlands and only to the use of HIV, chlamydia and syphilis self-tests.

available self-tests in the Netherlands and about the pros and cons of self-testing.

\section{INTRODUCTION}

Self-tests for HIV and other sexually transmitted infections (STIs) are tests that are collected, performed and interpreted autonomously by individuals wanting to know their HIV/STI status. ${ }^{2}$ Self-sampling tests differ from self-tests as they involve a laboratory for the analysis of self-collected specimens.

HIV self-tests may be a promising prevention strategy as they can lead to increased testing rates $^{1}{ }^{3-5}$ and safer sex practices. $^{6} 7$ Studies report good accuracy of unsupervised HIV self-testing and high user acceptability. ${ }^{13489}$ Despite legislation that prohibits over-the-counter sold HIV tests (including HIV self-tests), HIV self-tests are easily available through the internet in the Netherlands. ${ }^{10}$

Unlike self-sampling, where accuracy is shown to be high, ${ }^{11}$ few studies have evaluated the accuracy of STI self-tests other than 
HIV and the limited data available report alarmingly poor results. ${ }^{12} 13$ Also, there are concerns about the lack of linkage to counselling, treatment and care for HIV/ STI self-test users who test positive ${ }^{214}$ and the lack of clear information and/or instructions for self-tests that are currently available. ${ }^{101315}$ Due to these concerns, the National Institute for STI and AIDS Control in the Netherlands (STI AIDS Netherlands) currently recommends against the use of STI self-tests. ${ }^{10}$ However, like HIV tests, STI self-tests have already been easily available through the internet, at the pharmacy and drugstore for a number of years.

Due to the anonymous nature of self-testing, the extent to which commercially sold HIV/STI self-tests are used and determinants of usage are not well known. Studies among men having sex with men (MSM) in France in $2009^{16}$ and among attendees of a street-based HIV testing programme in Spain in $2010-2012^{17}$ found that $0.6-0.8 \%$ of participants had ever used an HIV self-test. A study among an internet panel in the Netherlands in 2006 found that $0.1 \%, 0.08 \%$ and $0.03 \%$ of participants had ever used a self-test for HIV, chlamydia and syphilis, respectively. ${ }^{18}$ In a study among online recruited MSM in China in 2013, 20\% reported HIV self-test usage. ${ }^{19}$ However, these studies were not designed to study the population-based prevalence of HIV/STI self-test usage or study trends over time. Furthermore, analyses of determinants of usage ${ }^{16-18}$ were restricted to HIV self-test or overall self-test usage, including non-HIV/STI self-tests, for example, for diabetes or cholesterol.

To gain insight into HIV and STI (ie, chlamydia and syphilis) self- test usage in the Netherlands, we studied (temporal trends in) HIV/STI self-test usage and its determinants among the general population and highrisk groups in Amsterdam, the Netherlands.

\section{METHODS}

\section{Study populations}

Between 2007 and 2015, data regarding HIV/STI self-test usage were collected in four different studies (S1-4) in Amsterdam, the Netherlands, among the general population (S1-2) and HIV-negative high-risk groups (S3-4) (table 1)

S1: Representative sample of Amsterdam residents participating in a serial cross-sectional Health Monitoring Survey

Every 4 years, a random sample of Amsterdam residents is drawn from the municipality register and asked to participate in a representative population-based cross-sectional Health Monitoring Survey conducted by the Public Health Service of Amsterdam. ${ }^{20}{ }^{21}$ Participants complete questionnaires (paper/online) on physical, mental and sexual health. Participants unable to fill in a questionnaire on paper or online and hard to reach groups are assisted by a trained interviewer. Participation rates in the Health Monitor Survey were 50\% in 2008 and $38 \%$ in 2012. Questions on HIV/STI self-tests usage were answered in the 2008 and 2012 surveys by participants aged 16-54 years and 19-64 years, respectively. To compare both waves, only participants aged between 19 and 54 years were included.

\section{S2: Participants of the multiethnic HELIUS Study}

The HEalthy LIfe in an Urban Setting (HELIUS) Study is a multiethnic population-based cohort study investigating mechanisms underlying ethnic differences in communicable and non-communicable diseases. ${ }^{22} \mathrm{~A}$ random sample of individuals aged 18-70 years old was drawn from the municipality register of Amsterdam, stratified by ethnicity, including those of Surinamese (with African Surinamese and South-Asian Surinamese as the

Table 1 Descriptive of the contributing studies for this manuscript

\begin{tabular}{|c|c|c|c|c|}
\hline Study & Study design & Study population & $\begin{array}{l}\text { Period of data } \\
\text { collection }\end{array}$ & $\mathbf{N}$ \\
\hline S1: The Health Monitoring Survey & $\begin{array}{l}\text { Serial cross- } \\
\text { sectional }\end{array}$ & $\begin{array}{l}\text { Representative sample of } \\
\text { Amsterdam residents }\end{array}$ & 2008 and 2012 & $\begin{array}{l}\text { Total: } 6044 \\
\text { 2008: } 2547 \\
\text { 2012: } 3497\end{array}$ \\
\hline $\begin{array}{l}\text { S2: The HEalthy Life in an Urban } \\
\text { Setting (HELIUS) Study }\end{array}$ & Cohort study & $\begin{array}{l}\text { Random sample of Amsterdam } \\
\text { residents from Surinamese, } \\
\text { Turkish, Moroccan, Ghanaian and } \\
\text { Dutch ethnic origin }\end{array}$ & $\begin{array}{l}\text { 2011-2015 } \\
\text { (baseline data) }\end{array}$ & Total: 17603 \\
\hline $\begin{array}{l}\text { S3: The Amsterdam Cohort } \\
\text { Studies (ACS) }\end{array}$ & Cohort study & HIV-negative MSM & 2008 and 2013 & $\begin{array}{l}\text { Total: } 597 \\
\text { 2008: } 447 \\
\text { 2013: } 469\end{array}$ \\
\hline S4: STI Clinic HIV Survey & $\begin{array}{l}\text { Serial cross- } \\
\text { sectional }\end{array}$ & $\begin{array}{l}\text { HIV-negative STI clients of } \\
\text { the Public Health Service of } \\
\text { Amsterdam }\end{array}$ & $\begin{array}{l}2007-2009 \text { and } \\
2012\end{array}$ & $\begin{array}{l}\text { Total: } 5655 \\
\text { Autumn 2007: } 949 \\
\text { Spring 2008: } 935 \\
\text { Autumn 2008: } 924 \\
\text { Spring 2009: } 935 \\
\text { Autumn 2009: } 911 \\
\text { Spring 2012: } 1001\end{array}$ \\
\hline
\end{tabular}


main ethnic groups), Turkish, Moroccan, Ghanaian and Dutch ethnic origin. Response rate (number participated/number invited) in the HELIUS Study was $28 \%$. Baseline data collection took place in 2011-2015. Participants underwent a physical examination and completed a self-administered questionnaire (paper/online), including questions on sexual health and HIV/STI selftest usage. Participants unable to fill in the questionnaire themselves were assisted by an ethnically matched trained interviewer. To compare results with the results of study 1 (representative sample of Amsterdam residents), only participants aged between 19 and 54 years were included in the analyses.

\section{S3: MSM participating in the Amsterdam Cohort Studies (ACS)}

The Amsterdam Cohort Studies (ACS) among MSM started in 1984 and is an open, prospective cohort study that investigates the epidemiology, pathogenesis, risk factors and effect of interventions concerning HIV/AIDS and other bloodborne infections and STIs in the Netherlands. ${ }^{23}$ Biannually, HIV-positive and HIV-negative participants complete questionnaires (paper/online) on sexual behaviour, give blood for HIV testing and storage and, since 2008, are tested for STI. HIV/STI self-test usage was measured in two waves (early 2008 and late 2013). For the present study, HIV-positive MSM were excluded (2008: $\mathrm{n}=88$; 2013: $\mathrm{n}=61$ ).

\section{S4: STI clinic clients participating in a serial cross-sectional survey} Biannually between 1991 and 2012, approximately 1000 visitors of the Amsterdam STI outpatient clinic of the Public Health Service were asked to participate in a cross-sectional survey, initially started to measure HIV prevalence and later also other (bloodborne) infections. ${ }^{25}{ }^{26}$ Participants were interviewed using standard questionnaires which included questions about risk factors for HIV and other infections and HIV/STI test behaviour. Participants received routine STI testing and were anonymously screened for HIV and from 2007 onwards also for other infections (eg, hepatitis C virus, human papilloma virus, herpes simplex virus). Participation rate varied between $65 \%$ and $96 \%$ over the years. Data on HIV/STI self-test usage were collected in six waves: Autumn 2007, Spring 2008, Autumn 2008, Spring 2009, Autumn 2009 and Spring 2012. For the present study, HIV-positive STI clinic clients were excluded $(\mathrm{n}=408)$.

We included only participants with available HIV/STI self-test data. S2-4 received institutional review board approval by the medical ethics committee of the Academic Medical Center of Amsterdam (S2: project number 10/100; S3: project number 07/182; S4: project number 06/257). For S1, approval by an ethics committee or institutional review board was not necessary according to Dutch legislation on medical research involving human subjects. Detailed information about the studies can be found elsewhere. ${ }^{20-26}$

\section{Variables}

Sociodemographics, sexual (risk) behaviour and self-test usage Age, ethnic origin, education level and sexual behaviour (testing behaviour, condomless intercourse, number of sexual partners, STI diagnosis) were obtained according to the individual study protocols. Non-Dutch ethnic origin was defined as being born outside the Netherlands with at least one parent who was also born outside the Netherlands (first-generation migrant) or being born in the Netherlands but with both parents born outside the Netherlands (second-generation migrant). ${ }^{27}$ In the HELIUS Study (S2), participants' ethnicity was based on their and their parents' country of birth. Surinamese subgroups (South-Asian Surinamese, African Surinamese, Javanese Surinamese and Surinamese other/unknown) were classified according to self-reported ethnic origin. Due to small numbers, Javanese Surinamese were included in the Surinamese other/unknown group. Age was grouped into four categories (16-24 years/25-29 years/30-34years/ $\geq 35$ years). Number of (lifetime) sexual partners was categorised based on tertiles. Condomless intercourse was defined as not always or never using a condom while practising vaginal and/or anal sex with casual partners. Among STI clinic clients (S4), this variable included both steady and casual partners since partner type was not measured.

HIV/STI self-test usage was defined as having used a HIV, chlamydia and/or syphilis self-test in the preceding 6 (S3: MSM participating in the ACS) or 12 months (S1-2: the general population and S4: STI clinic clients). We focussed on HIV, chlamydia and syphilis self-tests as at the start of the study these were the main HIV/STI self-tests available through the internet and/or pharmacies. In each study, self-tests were explained to participants as home tests that they had bought (eg, through the internet, at the pharmacy and/or at a drugstore) for self-use at home.

Additionally, general HIV/STI testing behaviour in the previous 12 and 6 months, including self-testing, was measured among the general population (S1-2), respectively. As our sexual risk groups (S3-4) received HIV/STI testing at the time and location of recruitment, general HIV/STI testing behaviour was not measured in these groups.

\section{Statistical analyses}

Within each study, we described study population characteristics and prevalence of self-test usage. Prevalence of self-test usage and 95\% CIs among the representative sample of Amsterdam residents (S1) were weighted by sex, age, district and in 2012 also for income, marital status, household size and ethnic origin to calculate the Amsterdam population-based prevalence of self-test usage. Time trend in HIV/STI self-test usage among the representative sample of Amsterdam residents (S1) was assessed by using $\mathrm{X}^{2}$ tests. In S2-4, Wilson intervals ${ }^{28}$ were used to determine $95 \%$ CIs as self-test usage prevalence was low. Time trend in HIV/STI self-test usage 
among STI clinic clients (S4) was assessed by logistic regression analyses using restricted cubic splines to take the non-linear time trend into account. For all analyses among MSM participating in the ACS (S3), we performed logistic regression analyses using generalised estimating equations to correct for repeated measurements. For participants of the multiethnic HELIUS Study (S2), no time trend was assessed. Among the general population (S1-2), we additionally calculated the proportion of self-test usage among participants who reported to have had an HIV/STI test in the previous 12 and 6 months, respectively.

Using univariable and multivariable logistic regression analyses, we assessed determinants of HIV/STI self-test usage. Despite our large sample sizes, we were unable to identify determinants for HIV and STI self-test usage separately because of the small numbers of HIV/STI self-test users. Determinants in the analyses included age, ethnic origin, education level, sexual risk behaviour and calendar year of data collection. For univariable and multivariable analyses, among the representative sample of Amsterdam residents (S1), no weighting was used. Determinants of self-test usage among participants of the multiethnic HELIUS Study (S2) were only assessed among those aged 18-34 years, because questions on sexual risk behaviour were optional for participants aged 35 years or older. Variables with a $\mathrm{p}$ value $<0.10$ in univariable analyses were included in the final multivariable models. We checked for interactions between the independent variables in the final models.

A $p$ value of $<0.05$ level was considered statistically significant. Analyses were performed using STATA Intercooled 13.1 (STATA Corporation, College Station, Texas, USA) and SPSS V.21 (SPSS, Chicago, USA).

\section{RESULTS}

\section{Characteristics}

In total, 29899 individuals were included in this study: 6044 inhabitants of Amsterdam (S1), 17603 participants of the multiethnic HELIUS Study (S2), 597 MSM participating in the ACS (S3) and 5655 STI clinic clients (S4) (table 1).

Of 6044 inhabitants of Amsterdam participating in the Health Monitoring Survey (S1), 2547 participated in 2008 and 3497 in 2012. Participants had a median age of 35 years (IQR: 28-45), 60\% (3621/6044) were women, $77 \%(4660 / 6044)$ had a college degree or higher, $58 \%$ (3486/6044) were of Dutch origin and 21\% (1288/6044) had been tested for HIV and/or STI in the previous 12 months.

Of 17603 participants of the multiethnic HELIUS Study (S2), the median age was 40 years (IQR: 30-48), $59 \%$ (10 339/17 603) were women, 27\% (4822/17 603) had a college degree or higher and 10\% (1794/17 603) were tested for HIV and/or STI in the previous 6 months. Seventeen per cent (3051/17 603) were of Dutch origin, 13\% (2353/17 603) of South-Asian Surinamese,
$16 \%(2875 / 17603)$ of African Surinamese, $2.0 \%$ $(352 / 17603)$ of other or unknown Surinamese origin, 20\% (3470/17 603) of Turkish, 20\% (3566/17 603) of Moroccan and 11\% (1905/17 603) of Ghanaian origin.

Of 597 MSM participating in the ACS (S3), 447 participated in early 2008 and 469 participated in late 2013 (319 MSM participated in both waves). Participants had a median age of 38 years (IQR: $33-43), 91 \%$ (543/597) had a college degree or higher and $79 \%(469 / 597)$ were of Dutch origin.

Of 5655 STI clinic clients participating in the cross-sectional survey STI Clinic HIV Survey (S4), 949 participated in Autumn 2007, 935 in Spring 2008, 924 in Autumn 2008, 935 in Spring 2009, 911 in Autumn 2009 and 1001 in Spring 2012. Participants had a median age of 26 years (IQR: 22-34), 46\% (2571/5655) were women, $50 \%(2852 / 5655)$ had a college degree or higher, $57 \%(3199 / 5655)$ were of Dutch origin and $13 \%(762 / 5655)$ were diagnosed with an STI at their visit.

\section{Prevalence of HIV/STI self-test usage}

Among the representative sample of Amsterdam residents (S1; table 2), HIV/STI self-test usage in the preceding 12 months increased from $0.9 \%$ (22/2547; 95\% CI: $0.6 \%$ to $1.4 \%)$ in 2008 to $1.3 \%$ (57/3497; $95 \%$ CI: $1.0 \%$ to $1.8 \%)$ in 2012 , respectively $(\mathrm{p}<0.001)$. This increase was primarily due to increases in chlamydia (2008: 0.7\%, 2012: $1.2 \%, \mathrm{p}<0.001)$ and syphilis self-test usage (2008: $0.1 \%$, 2012: $0.4 \%, \mathrm{p}<0.001)$. Among those who were tested for HIV/STIs in the preceding 12 months, 5.4\% (70/1288; 95\% CI: $4.3 \%$ to $6.8 \%$ ) used a self-test. This proportion significantly increased over time (2008: 3.7\%, 2012: 6.8\%, $\mathrm{p}=0.014$ ) and was higher among those of non-Dutch ethnicity, although borderline significant (Dutch: $4.4 \%$, non-Dutch: $6.9 \%, \mathrm{p}=0.056$ ).

Among participants of the multiethnic HELIUS Study (S2), $1.4 \%$ (245/17 603; 95\% CI: $1.2 \%$ to $1.6 \%)$ used an HIV/STI self-test in the preceding 12 months. Among those tested for HIV/STIs in the preceding 6 months, $8.8 \%$ (158/1794; $95 \%$ CI: $7.6 \%$ to $10 \%)$ used a self-test. The latter was significantly different between ethnic groups (Surinamese other/unknown 13\%, South-Asian Surinamese 12\%, African Surinamese 12\%, Dutch $8.4 \%$, Ghanaian 5.6\%, Moroccan 5.0\% and Turkish 4.6\%, $\mathrm{p}=0.001$ ).

Among MSM participating in the ACS (S3), HIV/ STI self-test usage in the preceding 6 months remained stable over time, $1.1 \%$ (5/447; 95\% CI: $0.5 \%$ to $2.6 \%)$ in 2008 and $1.3 \%$ (6/469; $95 \%$ CI: $0.6 \%$ to $2.8 \%)$ in 2013 $(\mathrm{p}=0.824)$.

Among STI clinic clients (S4), HIV/STI self-test usage in the preceding 12 months increased from $0.8 \%$ (8/949; $95 \%$ CI: $0.4 \%$ to $1.7 \%)$ in 2007 to $2.1 \%$ (21/1001; 95\% CI: $1.4 \%$ to $3.2 \%)$ in 2012 ( $\mathrm{p}<0.001)$. This increase was primarily due to an increase in chlamydia self-test usage (2007: 0.1\%, 2012: 1.8\%, $\mathrm{p}<0.001)$. 


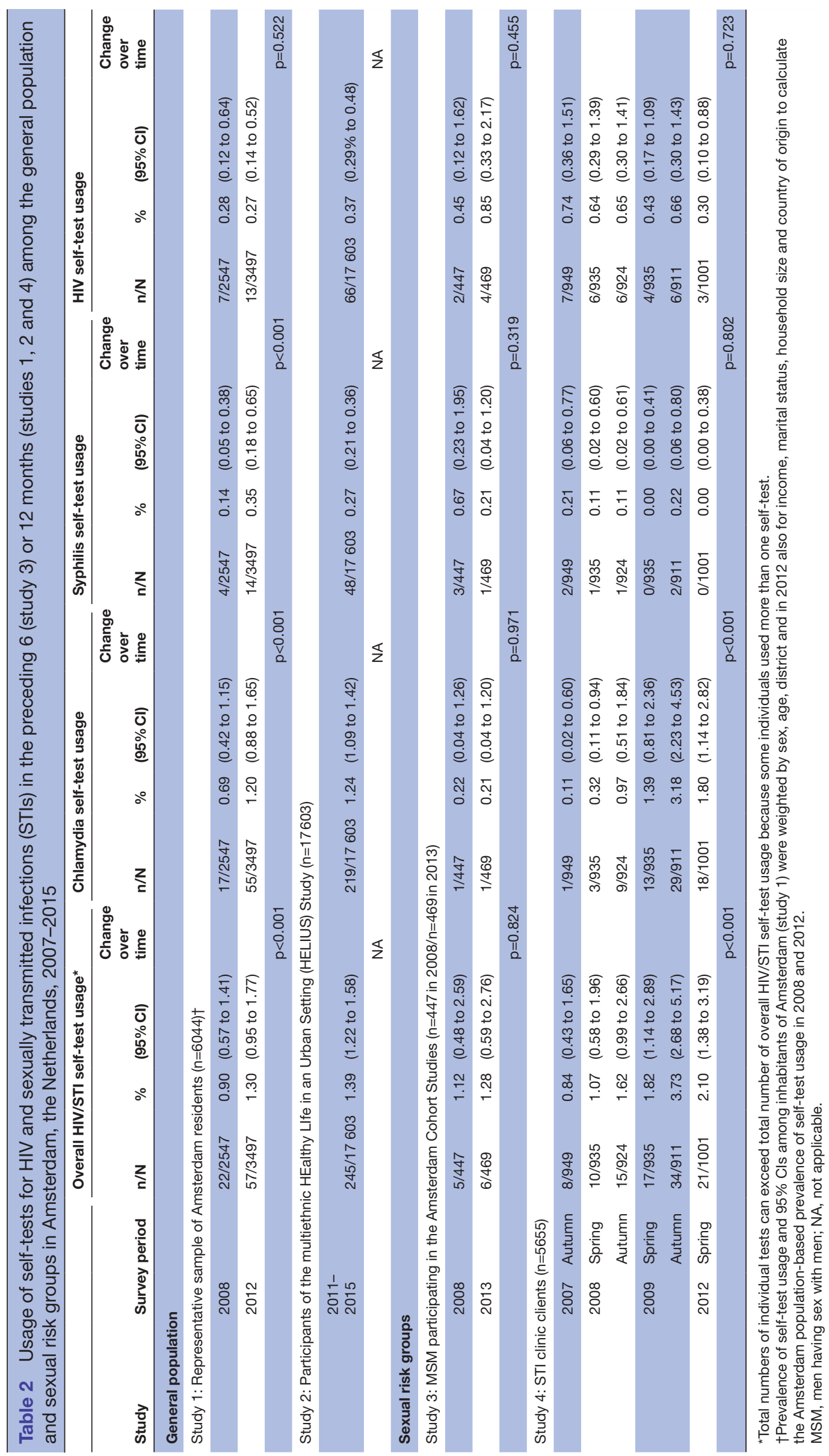


Table 3 Determinants associated with the usage of self-tests for HIV and sexually transmitted infections (STIs) in the previous 12 months among a representative sample of Amsterdam residents, 2008 and 2012, the Netherlands

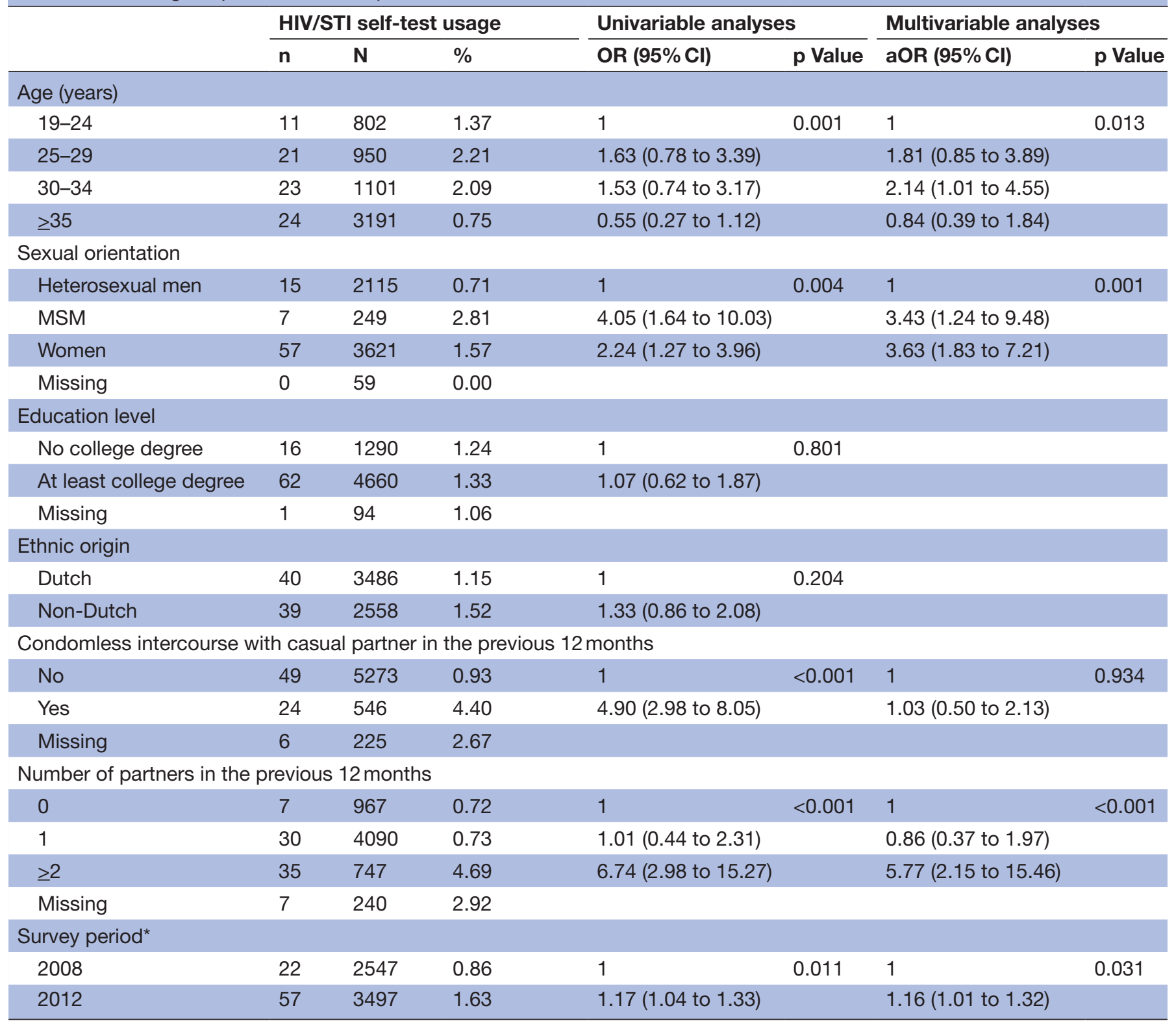

${ }^{*}$ The calculated prevalence and $95 \% \mathrm{Cl}$ were calculated based on unweighted numbers and therefore differ from the estimated presented in table 2.

(a)OR, (adjusted) OR; MSM, men having sex with men

Overall, chlamydia self-tests were most used, except among MSM participating in the ACS where HIV self-tests were most used.

\section{Determinants of HIV/STI self-test usage}

In multivariable analyses among the representative sample of Amsterdam residents (S1; table 3), only participants aged between 30 and 34 years (adjusted OR (aOR) 2.14 (95\% CI: 1.01 to 4.55$)$ ) were significantly more likely to have used self-tests compared with those aged between 19 and 24 years, whereas the aOR was 1.81 (95\% CI: 0.85 to 3.89 ) and 0.84 (95\% CI: 0.39 to 1.84) for those aged between $25-29$ years and $\geq 35$ years, respectively (overall $\mathrm{p}$ value 0.013 ). Also, MSM (aOR 3.43 (95\% CI: 1.24 to
9.48) ) and women (aOR 3.63 (95\% CI: 1.83 to 7.21$)$ ) were more likely to have used self-tests compared with heterosexual men. Those reporting one or more sexual partners in the preceding 12 months (one partner: aOR 0.86 (95\% CI: 0.37 to 1.97 ); $>2$ partners: aOR 5.77 (95\% CI: 2.15 to 15.46)) were more likely to have used self-tests compared with participants reporting no partners. As described above, self-test usage was higher in 2012 compared with 2008 (aOR 1.16 (95\% CI: 1.01 to 1.32)).

Among participants of the multiethnic HELIUS Study (S2; table 4), participants aged between 30 and 34 years (aOR 0.59 (95\% CI: 0.39 to 0.90$)$ ) were less likely to have used self-tests compared with participants aged 19-24 
Table 4 Determinants associated with the usage of self-tests for HIV and sexually transmitted infections (STIs) in the previous 12 months among participants of the multiethnic HEalthy LIfe in an Urban Setting (HELIUS) Study between 2011 and 2015 ,

Amsterdam, the Netherlands

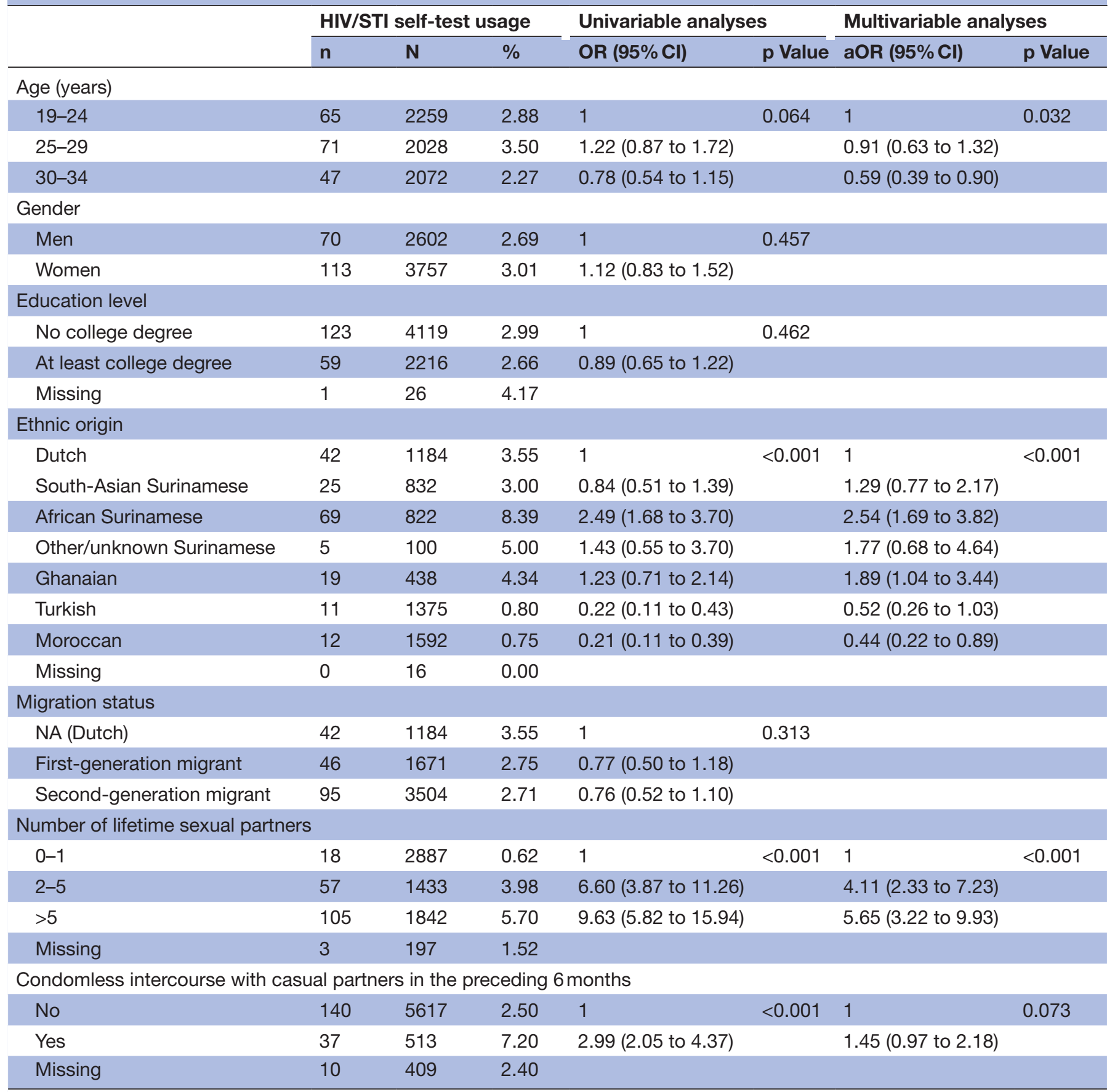

(a)OR, (adjusted) OR; NA, not applicable

years, whereas the aOR was 0.91 (95\% CI: 0.63 to 1.32 ) for those aged between 25 and 29 years (overall $p$ value 0.032). African Surinamese (aOR 2.54 (95\% CI: 1.69 to $3.82)$ ) and Ghanaian participants (aOR 1.89 (95\% CI: 1.04 to 3.44)) were more likely to have used self-tests compared with Dutch participants, whereas Moroccan participants (aOR 0.44 (95\% CI: 0.22 to 0.89 )) were less likely to have used self-tests (overall $\mathrm{p}$ value $<0.001$ ). Also, those reporting $\geq 2$ lifetime sexual partners ( $2-5$ partners: aOR 4.11 (95\% CI: 2.33 to 7.23 ); $>5$ partners: aOR 5.65
(95\% CI: 3.22 to 9.93)) were more likely to have used self-tests compared with participants reporting $<2$ sexual partners.

Among MSM participating in the ACS (S3; table 5), those reporting 3-8 casual partners in the preceding 6 months (unadjusted OR 9.86 (95\% CI: 1.21 to 80.55)) were more likely to have used self-tests compared with participants reporting $<3$ casual partners, whereas the OR $1.32(95 \%$ CI: 0.08 to 21.18 ) was for those reporting $>8$ casual partners (overall $p$ value 0.028 ). 
Table 5 Determinants associated with the usage of self-tests for HIV and sexually transmitted infections (STIs) in the previous 6 months among HIV-negative men having sex with men participating in the Amsterdam Cohort Studies in 2008 and 2013 , Amsterdam, the Netherlands

\begin{tabular}{|c|c|c|c|c|c|}
\hline & \multicolumn{3}{|c|}{ HIV/STI self-test usage } & \multicolumn{2}{|l|}{ Univariable analyses } \\
\hline & $\mathbf{n}$ & $\mathbf{N}$ & $\%$ & OR (95\% CI) & p Value \\
\hline \multicolumn{6}{|l|}{ Age (years) } \\
\hline $18-29$ & 3 & 124 & 2.42 & 1 & 0.334 \\
\hline $30-34$ & 3 & 198 & 1.52 & $0.62(0.12$ to 3.14$)$ & \\
\hline$\geq 35$ & 5 & 194 & 2.58 & 0.34 (0.08 to 1.45$)$ & \\
\hline \multicolumn{6}{|l|}{ Education level } \\
\hline No college degree & 2 & 93 & 2.15 & 1 & 0.384 \\
\hline At least college degree & 9 & 823 & 1.09 & 0.5 (0.11 to 2.36$)$ & \\
\hline \multicolumn{6}{|l|}{ Ethnic origin } \\
\hline Dutch & 9 & 731 & 1.23 & 1 & 0.821 \\
\hline Non-Dutch & 2 & 136 & 1.47 & 1.20 (0.26 to 5.59$)$ & \\
\hline Missing & 0 & 49 & 0.00 & & \\
\hline \multicolumn{6}{|c|}{ Number of sexual partners in the previous 6 months } \\
\hline $0-2$ & 1 & 672 & 0.15 & 1 & $<0.001$ \\
\hline $3-8$ & 7 & 206 & 3.40 & $6.60(3.87$ to 11.26$)$ & \\
\hline$>8$ & 1 & 38 & 2.63 & $9.63(5.82$ to 15.94$)$ & \\
\hline Missing & 2 & 916 & 0.22 & & \\
\hline \multicolumn{6}{|c|}{ Condomless intercourse with casual partners in the preceding 6 months } \\
\hline No & 6 & 672 & 0.89 & 1 & 0.028 \\
\hline Yes & 4 & 206 & 1.94 & $9.86(1.21$ to 80.55$)$ & \\
\hline Missing & 1 & 38 & 2.63 & 1.32 (0.08 to 21.18$)$ & \\
\hline \multicolumn{6}{|l|}{ Survey period } \\
\hline 2008 & 5 & 447 & 1.12 & 1 & 0.824 \\
\hline 2013 & 6 & 469 & 1.28 & $1.03(0.81$ to 1.31$)$ & \\
\hline
\end{tabular}

Among STI clinic clients (S4; table 6), MSM (unadjusted OR 2.37 (95\% CI: 1.31 to 4.29 )) and women (unadjusted OR 2.32 (95\% CI: 1.39 to 3.86$)$ ) were more likely to have used self-tests compared with heterosexual men. In multivariable analyses among STI clinic clients, a statistically significant interaction between sexual orientation and calendar period was found $(p=0.032)$. Self-test usage significantly increased over time among women (2007: $0.4 \%, 2012: 3.1 \%, \mathrm{p}<0.001)$, whereas the increase among heterosexual men and decrease among MSM were not statistically significant.

\section{DISCUSSION}

This study shows that the prevalence of HIV/STI self-test usage in the preceding 6-12 months among both the general population and high-risk groups in Amsterdam, the Netherlands, is relatively low (1-2\%). However, chlamydia and syphilis self-test usage increased over time among a representative sample of Amsterdam residents (S1) and chlamydia self-test usage increased over time among STI clinic clients (S4).
The overall low HIV/STI self-test usage among the general population and sexual risk groups is in line with findings from other European studies on HIV self-testing (France; Spain) ${ }^{16}{ }^{17}$ and on HIV/STI self-testing (the Netherlands). ${ }^{18}$ However, in a study from China, $20 \%$ of MSM reported prior HIV self-testing. ${ }^{19}$ The difference between Europe and China on HIV self-test usage can be explained by legal restrictions on selling HIV self-tests. In China, HIV self-test can be legally sold, whereas in France, Spain and the Netherlands, there were legal restrictions on HIV self-tests at the time the studies were conducted. In France, HIV self-tests became legally available in 2015, after the study on HIV self-test usage was conducted. ${ }^{1}$

Although we found an overall low HIV/STI self-test usage in the general population, $5-9 \%$ of the individuals who tested for HIV/STI in the preceding 6 or 12 months used a self-test. This finding indicates that although selftesting is currently not recommended by the National Institute for STI and AIDS control in the Netherlands (STI AIDS Netherlands), ${ }^{10}$ a substantial proportion opt for self-testing as their method of testing. Furthermore, our study shows HIV/STI self-test usage was higher among 


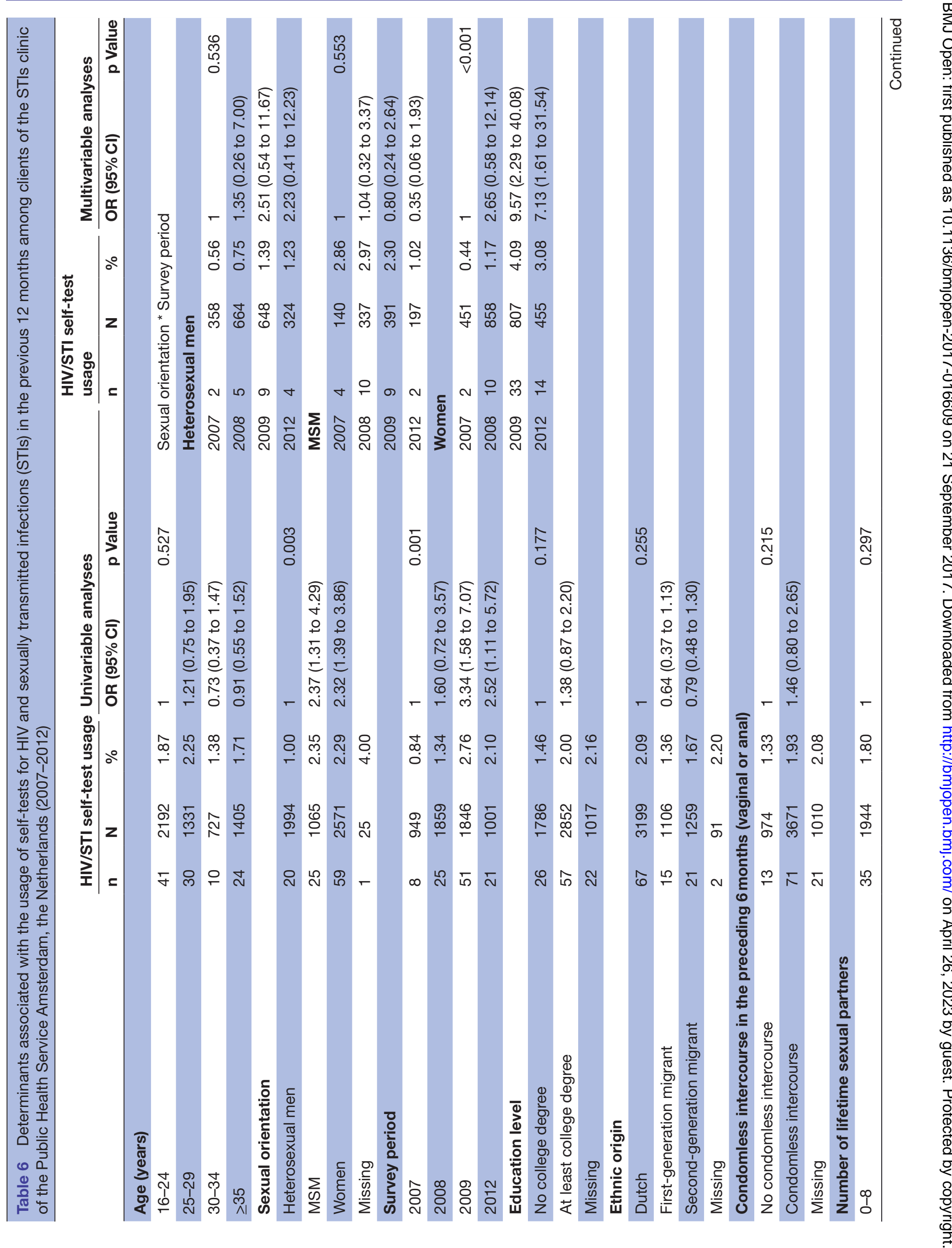




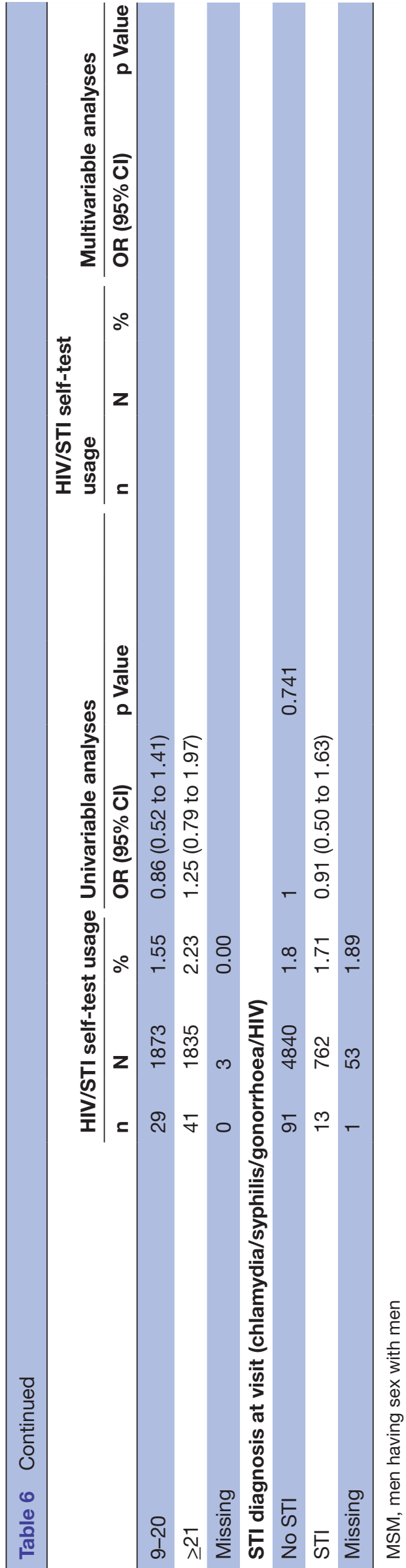

women and MSM compared with heterosexual men in the representative sample of Amsterdam residents and among STI clinic clients. These results are consistent with results that women and MSM are in general more likely to test for HIV and STI compared with heterosexual men. ${ }^{20}$ Heterosexual men might perceive themselves at lower risk for HIV/STI than women and MSM and therefore less often test for HIV/STI. It might also be that heterosexual men experience greater barriers to test for HIV/STI. Among the general population and MSM participating in the ACS, also a higher number of sexual partners were associated with higher self-test usage, suggesting selftests might be used by individuals at higher risk of HIV/ STI and therefore may be reaching the relevant populations. ${ }^{29}$ Among participants of the multiethnic HELIUS Study, we found that individuals of African Surinamese or Ghanaian origin were more likely to use self-tests. In addition, among HELIUS Study participants who have tested for HIV/STI in the preceding 12 months, individuals of Surinamese origin (all subgroups: South-Asian, African and other/unknown Suriname origin) more often opted for the use of a self-test compared with other ethnic groups. It might be that individuals of Surinamese or Ghanaian origin more often experience barriers to test at regular facilities than the other groups and therefore more often opt for self-testing. This might suggest that self-testing could increase HIV/STI test uptake among these groups, but this should be further explored in future studies. Also, it might be that individuals of Surinamese or Ghanaian origin are more aware of the availability of HIV/STI self-tests. This association between self-testing and ethnic origin was not found among the representative sample of Amsterdam residents (S1) and our sexual risk groups (S3-4). This is most likely because in these studies we grouped all non-Dutch origin ethnicities together because of small numbers.

Although we found an association between age and selftest usage in the two studies among the general population, this association was not found among the sexual risk groups. However, the results with regard to age and selftesting among the representative sample of Amsterdam residents and among the participants of the multiethnic HELIUS Study were inconsistent.

The low HIV/STI self-test usage among our high-risk groups can be explained by our data sources, since we included individuals who attended the Public Health Service's HIV/STI testing facilities and MSM participating in the ACS who were offered structural biannual HIV/STI testing. These individuals may have overcome testing barriers related to these facilities and therefore be less likely to opt for self-testing.

Our study shows that in recent years chlamydia selftests are most commonly used in all study groups except for MSM participating in the ACS. This could be due to higher self-perceived risk of chlamydia; one of the most prevalent and well-known STIs among heterosexuals. ${ }^{29}$ Furthermore, we found that increases in chlamydia selftest usage are primarily responsible for the observed 
overall increases of HIV/STI self-test usage among Amsterdam inhabitants and STI clinic clients. Our data cannot ascertain whether increased availability of chlamydia self-tests led to their increased usage. However, an increase in awareness of chlamydia self-testing is another plausible explanation, especially considering a chlamydia screening implementation programme that was conducted between 2008 and 2010, in which all 16-year-old to 29-year-old residents in Amsterdam and other cities were informed about chlamydia and invited to apply for a free self-sampling test kit. ${ }^{30} 31$ Although the participation rate in this screening programme was low $(16 \%)^{30} 31$ and self-sampling tests differ from self-tests, this may have increased general awareness about availability of self-tests and therefore explain the peak of selftest usage seen in 2009 among STI clinic clients.

HIV self-testing may be a valuable (additional) strategy to reach risk groups for testing, as highly accurate selftests are available and acceptability is high among key groups. ${ }^{192}$ Some countries, for example, France, UK and USA have already approved an HIV self-test for sale. ${ }^{133} 34$ The Netherlands has not authorised HIV self-tests for sale, but from 2014 to 2015 HIV self-tests were offered in combination with online counselling in a pilot study targeting MSM and migrants from HIV endemic countries. ${ }^{35}$ Preliminary results of this pilot study and other studies show that a large proportion of HIV self-test users have never or not recently been tested for HIV. ${ }^{31635}$ This suggests HIV self-testing programmes can be of additional value to increase testing rates among individuals not reached at regular testing facilities. However, this might only be true for individuals who are aware of their HIV risk. Additional interventions are needed to promote HIV testing among those individuals at risk for an HIV infection who are unaware of their risk. ${ }^{36}$ Also, it is important when implementing HIV self-testing programmes that highly accurate HIV self-tests and counselling and linkage to care are offered. ${ }^{137}$

For STIs other than HIV, the accuracy of currently available self-tests is less clear. Previous studies have shown that the accuracy of chlamydia self-tests is low and tests have been sold without proper instructions and information. ${ }^{10} 1213$ The observed increase in chlamydia self-test usage is concerning. Therefore, it is important to gain insight into the accuracy of currently available STI selftests. Furthermore, it is important to continue monitoring self-test usage and informing the public about the unknown accuracy and the pros and cons of self-testing.

The strengths of this study are the large sample size and that we were able to assess HIV/STI self-test usage in both the general population and sexual risk groups. However, some limitations need to be addressed. First, the results are limited to the population of Amsterdam, an urban population with nearby access to a free-of-cost HIV/STI testing service for HIV/STI risk groups at the Public Health Service, and therefore less generalisable to other, for example, more rural settings. Second, individuals participating in health-related research might not be representative of the general population. However, we were able to calculate population-based estimates by applying weighting among the sample of Amsterdam inhabitants (S1) and were able to estimate self-test usage among a multiethnic population in Amsterdam (S2), a group that is often under-represented in health-related research. Third, we were unable to identify determinants for HIV, chlamydia and syphilis self-test usage separately due to small numbers. Determinants may differ across different STIs, for example, MSM might be more likely to use HIV self-tests, whereas women might be more likely to use chlamydia self-tests. Fourth, we only focussed on HIV, chlamydia and syphilis self-tests. Currently, other STI selftests are available (eg, gonorrhoea self-test). Although this study gives an indication of the overall self-test usage, future studies should include other self-tests available.

In conclusion, overall HIV/STI self-test usage in Amsterdam, the Netherlands, is relatively low. However, chlamydia and syphilis self-test usage increased over time among the representative sample of Amsterdam residents and chlamydia self-test usage increased over time among STI clinic clients. Furthermore, a substantial proportion of persons in the general population who had been tested for HIV/STI reported the use of a selftest and we found higher self-test usage among participants of Surinamese or Ghanaian origin. It is important to continue monitoring self-test usage and informing the public about the unknown quality of current self-tests available and regarding pros and cons of self-testing. Also, motives for self-test usage among different ethnic groups should be further explored in future studies. Selftesting programmes can be a valuable additional strategy for public health professionals to address the needs of certain risk groups and increase testing rates, and the higher HIV/STI self-test usage among those at higher risk for HIV/STI in the general population suggests that selftest programmes might have an appeal to these groups. When implementing such programmes, it is however imperative that high-quality tests are used and alternative counselling (eg, online) and linkage to care are offered.

\section{Author affiliations}

${ }^{1}$ Department of Infectious Diseases Research and Prevention, Public Health Service of Amsterdam, The Netherlands

${ }^{2}$ Department of Internal Medicine, Division of Infectious Diseases, Center for Infection and Immunology Amsterdam (CINIMA), Academic Medical Center (AMC), University of Amsterdam, The Netherlands

${ }^{3}$ Department of Epidemiology and Health Promotion, Public Health Service of Amsterdam, The Netherlands

${ }^{4}$ Sexually Transmitted Infections Outpatient Clinic, Public Health Service of Amsterdam, The Netherlands

${ }^{5}$ Department of Public Health/Department of Clinical Epidemiology, Biostatistics and Bioinformatics, Academic Medical Center (AMC), University of Amsterdam, The Netherlands

Acknowledgements The authors acknowledge all participants of the different studies for their contribution, research teams for data collection and data management, Darshni Jhagroe for helping with the analyses of the study 4, Ronald Geskus for statistical advice, Claire Buswell for editing the final manuscript and the funders for the financial support. 
Contributors JPB interpreted the data and wrote the draft manuscript. FRZ designed and supervised the overall study and contributed to the analyses and interpretation of the data. MP, IGS, HD, TH, MBS and UD provided contributions to the data collection and management in the different studies. All authors provided substantial contributions to the interpretation of the data and to subsequent drafts and approved the final version of the manuscript.

Funding Funding for the present study was received from the Public Health Service of Amsterdam's (PHSA) Research and Development Fund (project number 07-13). The population-based cross-sectional Health Monitoring Survey is financially supported and conducted by the PHSA. The HEalthy Llfe in an Urban Setting (HELIUS) Study is conducted by the Academic Medical Center (AMC) in Amsterdam and the PHSA. Both organisations provide core support for HELIUS. The HELIUS Study is also funded by the Dutch Heart Foundation (grant number 2010T084), the Netherlands Organisation for Health Research and Development (ZonMw; grant number 200500003) and the European Union (FP-7; grant number 278901). The Amsterdam Cohort Studies (ACS) on HIV infection and AIDS, which is a collaboration between the PHSA, the AMC/the University of Amsterdam, Sanquin Blood Supply Foundation, Medical Center Jan van Goyen and the HIV Focus Center of the DC-Clinics, is part of the Netherlands HIV Monitoring Foundation and financially supported by the Center for Infectious Disease Control of the Netherlands National Institute for Public Health and the Environment. The cross-sectional survey among clients of the PHSA's sexually transmitted infection outpatient clinic was funded by the Center for Infectious Disease Control of the Netherlands National Institute for Public Health and the Environment and the PHSA's Research and Development Fund. The funders of the present study had no role in its design, data collection and analysis, decision to publish or preparation of the manuscript.

Competing interests MP, UD and FRZ have received non-financial support (ie, HIV self-test kits) from OraSure Technologies for another (investigator initiated) study concerning HIV self-testing.

Ethics approval The medical ethics committee of the Academic Medical Center of Amsterdam.

Provenance and peer review Not commissioned; externally peer reviewed. Data sharing statement Additional data are available upon request.

Open Access This is an Open Access article distributed in accordance with the Creative Commons Attribution Non Commercial (CC BY-NC 4.0) license, which permits others to distribute, remix, adapt, build upon this work non-commercially, and license their derivative works on different terms, provided the original work is properly cited and the use is non-commercial. See: http://creativecommons.org/ licenses/by-nc/4.0/

(c) Article author(s) (or their employer(s) unless otherwise stated in the text of the article) 2017. All rights reserved. No commercial use is permitted unless otherwise expressly granted.

\section{REFERENCES}

1. World Health Organization. Guidelines on HIV Self-Testing and Partner Notification: Supplement to Consolidated Guidelines on HIV Testing Services. Geneva: World Health Organization, 2016.

2. Joint United Nations Programme on HIV/AIDS, World Health Organization. A short technical update on self-testing for HIV. Geneva: Joint United Nations Programme on HIV/AIDS, 2013.

3. Krause J, Subklew-Sehume F, Kenyon C, et al. Acceptability of HIV self-testing: a systematic literature review. BMC Public Health 2013;13:735

4. Pant Pai N, Sharma J, Shivkumar S, et al. Supervised and unsupervised self-testing for HIV in high- and low-risk populations: a systematic review. PLoS Med 2013;10:e1001414.

5. Johnson CC, Kennedy C, Fonner V, et al. Examining the effects of HIV self-testing compared to standard HIV testing services: a systematic review and meta-analysis. J Int AIDS Soc 2017;20:1-10.

6. Balán IC, Carballo-Diéguez A, Frasca T, et al. The impact of rapid HIV home test use with sexual partners on subsequent sexual behavior among men who have sex with men. AIDS Behav 2014;18:254-62.

7. Martinez $\mathrm{O}$, Carballo-Diéguez A, Ibitoye $\mathrm{M}$, et al. Anticipated and actual reactions to receiving HIV positive results through self-testing among gay and bisexual men. AIDS Behav 2014;18:2485-95.

8. Figueroa C, Johnson C, Verster A, et al. Attitudes and Acceptability on HIV Self-testing Among Key Populations: A Literature Review. AIDS Behav 2015;19:1949-65.

9. Stevens DR, Vrana CJ, Dlin RE, et al. A Global Review of HIV Selftesting: Themes and Implications. AIDS Behav 2017.
10. Pars L, van Bergen J. Soa-testen, zelf doen of laten (doen)? [Dutch]. Amsterdam: SOA AIDS Nederland, 2013.

11. Lunny C, Taylor D, Hoang L, et al. Self-Collected versus ClinicianCollected Sampling for Chlamydia and Gonorrhea Screening: A Systemic Review and Meta-Analysis. PLoS One 2015;10:e0132776.

12. van Dommelen L, van Tiel FH, Ouburg S, et al. Alarmingly poor performance in Chlamydia trachomatis point-of-care testing. Sex Transm Infect 2010;86:355-9.

13. Owens SL, Arora N, Quinn N, et al. Utilising the internet to test for sexually transmitted infections: results of a survey and accuracy testing. Sex Transm Infect 2010;86:112-6.

14. Napierala Mavedzenge S, Baggaley R, Corbett EL. A review of self-testing for HIV: research and policy priorities in a new era of HIV prevention. Clin Infect Dis 2013;57:126-38.

15. Bustamante MJ, Konda KA, Joseph Davey D, et al. HIV self-testing in Peru: questionable availability, high acceptability but potential low linkage to care among men who have sex with men and transgender women. Int J STD AIDS 2017;28.

16. Greacen T, Friboulet D, Fugon L, et al. Access to and use of unauthorised online HIV self-tests by internet-using French-speaking men who have sex with men. Sex Transm Infect 2012;88:368-74.

17. Belza MJ, Figueroa C, Rosales-Statkus ME, et al. Low knowledge and anecdotal use of unauthorized online HIV self-test kits among attendees at a street-based HIV rapid testing programme in Spain. Int J Infect Dis 2014;25:196-200.

18. Ronda G, Portegijs P, Dinant GJ, et al. Use of diagnostic self-tests on body materials among Internet users in the Netherlands: prevalence and correlates of use. BMC Public Health 2009;9:100.

19. Han L, Bien $\mathrm{CH}$, Wei C, et al. HIV self-testing among online MSM in China: implications for expanding HIV testing among key populations. J Acquir Immune Defic Syndr 2014;67:216-21.

20. Geneeskundige en Gezondheidsdienst (GGD) Amsterdam. Amsterdamers gezond en wel? Amsterdamse Gezondheidsmonitor 2012 [Dutch]. Amsterdam: Geneeskundige en Gezondheidsdienst (GGD) Amsterdam, 2013.

21. Dijkshoorn H, van Dijk TK, Janssen AP. Zo gezond is Amsterdam! Eindrapport Amsterdamse Gezondheidsmonitor 2008 [Dutch]. Amsterdam: Geneeskundige en Gezondheidsdienst (GGD) Amsterdam, 2009.

22. Stronks K, Snijder MB, Peters RJ, et al. Unravelling the impact of ethnicity on health in Europe: the HELIUS study. BMC Public Health 2013;13:402.

23. van Griensven GJ, de Vroome EM, Goudsmit J, et al. Changes in sexual behaviour and the fall in incidence of HIV infection among homosexual men. BMJ 1989;298:218-21.

24. Matser A, Prins M. The Amsterdam Cohort Studies on HIV infection: annual report 2015. In: van Sighem Al, Boender S, Smit C, eds. et alHuman Immunodeficiency Virus (HIV) Infection in the Netherlands: HIV Monitoring Report. Amsterdam: Stichting HIV monitoring, 2016.

25. van den Hoek JA, Fennema JS, van Haastrecht HJ, et al. HIVprevalentie bij bezoekers van een polikliniek voor seksueel overdraagbare aandoeningen en bij een groep prostituées en prostituanten [Dutch]. Ned Tijdschr Geneeskd 1992;136:1813-8.

26. Urbanus AT, Van De Laar TJ, Geskus R, et al. Trends in hepatitis $C$ virus infections among MSM attending a sexually transmitted infection clinic; 1995-2010. AIDS 2014;28:781-90.

27. Statistics Netherlands. Definitions: People with a foreign background. 2015. available at http://www.cbs.nl/en-GB/menu/ themas/dossiers/allochtonen/methoden/begrippen/default.htm? Languageswitch $=$ on\&ConceptID $=315$ (accessed on 5 November 2015).

28. Brown LD, Cai TT, DasGupta A. Interval estimation for a binomial proportion. Statistical Science 2001;16:101-17.

29. van den Broek IVF, van Aar F, van Oeffelen AAM, et al. Sexually transmitted infections in the Netherlands in 2015. Bilthoven: National Institute for Public Health and the Environment, 2016.

30. van Bergen JE, Fennema JS, van den Broek IV, et al. Rationale, design, and results of the first screening round of a comprehensive, register-based, Chlamydia screening implementation programme in the Netherlands. BMC Infect Dis 2010;10:293.

31. van den Broek IV, Hoebe CJ, van Bergen JE, et al. Evaluation design of a systematic, selective, internet-based, Chlamydia screening implementation in the Netherlands, 2008-2010: implications of first results for the analysis. BMC Infect Dis 2010;10:89.

32. Flowers P, Riddell J, Park C, et al. Preparedness for use of the rapid result HIV self-test by gay men and other men who have sex with men (MSM): a mixed methods exploratory study among MSM and those involved in HIV prevention and care. HIV Med 2017;18:245-55.

33. The Guardian. HIV self-testing kit goes on sale in UK. available at http://www.theguardian.com/society/2015/apr/27/hiv-self-testing-kiton-sale-uk-biosure (accessed on 1 Nov 2016). 
34. US Food and Drug Administration (FDA). OraQuick In-Home HIV Test: Summary of Safety and Effectivenesshttp://www.fda.gov/ downloads/BiologicsBloodVaccines/BloodBloodProducts/Approve dProducts/PremarketApprovalsPMAs/UCM312534.pdf (accessed on 25 Feb 2015).

35. Zuure FR, van der Helm J, van Bergen J, et al. Home testing for HIV succeeds in reaching first-time and infrequent testers in the Netherlands: results of the HIVTest@Home trial [abstract]. The international AIDS conference. 18-22 July 2016 Durban, South Africa 2016.
36. Flowers $\mathrm{P}$, Estcourt $\mathrm{C}$, Sonnenberg $\mathrm{P}$, et al. HIV testing intervention development among men who have sex with men in the developed world. Sex Health 2017:80.

37. Greacen T, Kersaudy-Rahib D, Le Gall JM, et al. Comparing the Information and Support Needs of Different Population Groups in Preparation for 2015 Government Approval for HIV Self-testing in France. PLoS One 2016;11:e0152567. 